\title{
Development and Validation of Novel Stability- Indicating LC Method for the Determination of Saxagliptin and Metformin
}

\author{
Sachin Bhanudas Gurav*, Neela Manish Bhatia \\ Bharati Vidyapeeth College of Pharmacy, Kolhapur, Maharashtra, INDIA.
}

\begin{abstract}
Aim: Development of a novel precise, selective and sensitive stability indicating RPHPLC method has been developed and validated for the determination of Saxagliptin hydrochloride (SAX) and Metformin $\mathrm{HCl}$ (MET) in bulk drug and pharmaceutical dosage form. Materials and Methods: The separation was carried out on a Phenomenex Luna, SCX, $250 \times 4.6 \mathrm{~mm}, 10 \mu \mathrm{m}$ using a mobile phase of ammonium dihydrogen phosphate buffer $\mathrm{pH}$ 2.50: methanol [70:30 \% v/v]. Quantitation was achieved using UV detection at $210 \mathrm{~nm}$. Results: The retention times were about $6.2 \mathrm{~min}$ for SAX and about $10.4 \mathrm{~min}$ for MET. Calibration curves were linear over the concentration range from $5-100 \mu \mathrm{g} / \mathrm{mL}$ for SAX and $40-800 \mu \mathrm{g} / \mathrm{mL}$ for MET. Peak purity of SAX and MET established in presence of all major degradation product in stressed samples. Conclusion: The proposed method of analysis has been validated as per $\mathrm{ICH}$ guidelines and proved to be specific, precise, linear, rugged and robust. The effectiveness of the method was demonstrated with marketed pharmaceutical preparation of SAX and MET.
\end{abstract}

Key words: Saxagliptin, Metformin, Stability indicating, Forced degradation, Pharmaceutical preparation.

\section{INTRODUCTION}

Saxagliptin (SAX), (1S,3S,5S)-2-[(2S)2-amino-2-(3-hydroxy-1- adamantyl) acetyl]-2-azabicyclo[3.1.0] hexane-3carbonitrile, (Figure 1a) is an inhibitor of dipeptidyl peptidase-4 (DPP-4) used as oral hypoglycemic drug for the management of type 2 diabetes mellitus. Saxagliptin is indicated as an addition to diet and exercise to get better glycemic control in patients with type 2 diabetes. It is available commercially as Onglyza tablets and also in mixture with Metformin as KOLMBIGLYZE XR tablets. ${ }^{1}$ Metformin hydrochloride (MET), N, N-dimethylimidodicarbonimidic diamide hydrochloride [Figure 1b] is an antidiabetic drug in the biguanide class that induces glycolysis in peripheral tissues. ${ }^{2}$ Pharmaceutical preparation containing
SAX and MET, used in the management of type 2 diabetes.

Literature review reveals that methods are available for simultaneous determination of SAX and MET in combination by using Spectrophotometric ${ }^{3}$ and Chromatographic ${ }^{4-7}$ technique. Several methods for Metformin $\mathrm{HCl}$ alone and in combination with other drugs are also available those includes Spectrophotometric ${ }^{8}$ and HPLC. ${ }^{9-21}$ There are some chromatographics methods available for $\mathrm{SAX}^{22-27}$ some electrochemical methods are also reported for determination of Metformin and Saxagliptin. ${ }^{28-30}$

A stability-indicating method identify and estimates the analytes specifically with good resolution with its degradants in forced degradation study. As per ICH guidelines
Submission Date: 20-09-2019; Revision Date: 13-11-2019; Accepted Date: 14-04-2020

DOI: 10.5530/ijper.54.2s.93 Correspondence:

Mr. Sachin Bhanudas Gurav Bharati Vidyapeeth College of Pharmacy, Kolhapur416013, Maharashtra, INDIA. Phone: +91-0231-2637286 E-mail: guravsachinresearch@gmail.com

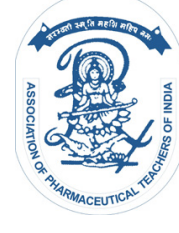

www.ijper.org 
it's a prerequisite of development of stability-indicating method. The guidelines clearly require the conduction of forced degradation studies beneath different conditions, like acidic hydrolysis, alkali hydrolysis, photolysis, oxidation, Thermal, etc. and resolution of the analyte from degradant impurities. The chromatographic purity of analyte peak in degradation samples is must for the validation of the any method and this is the most important when development of any stability-indicating method.

In present study, a simple stability indicating method for quantification of SAX and MET has been developed and validated. Stability indicating nature of the method has been established in stressed samples and successfully applied for a pharmaceutical preparation.

\section{MATERIALS AND METHODS}

\section{Instrumentation}

Agilent 1200 series equipped with quaternary pump, autosampler and DAD detector was used. The data processing was done by using AGILENT Open Lab software. The chromatographic separations were performed on a Phenomenex Luna SCX column (250 x $4.6 \mathrm{~mm}$ i.d., $10 \mu \mathrm{m}$ particle size) as a stationary phase and ammonium dihydrogen phosphate buffer $(\mathrm{pH}$ 2.50): Methanol [70:30 \% v/v] as mobile phase. A 10 $\mu \mathrm{L}$ sample solutions were injected to chromatographic system using autosampler system. The flow rate of 1.8 $\mathrm{mL} / \mathrm{min}$ and detection wavelength of $210 \mathrm{~nm}$ was taken for analysis. The column temperature and autosampler temperature was kept at $40^{\circ} \mathrm{C}$ and $10^{\circ} \mathrm{C}$ respectively.

Denver analytical balance was used for weighing and $\mathrm{pH}$ measurement was performed by using Lab India $\mathrm{pH}$ meter. Mobile phase filtration was performed by vacuubrand $2^{\circ} \mathrm{C}$ vacuum pump using $0.45 \mu \mathrm{m}$ nylon membrane filter paper. Specificity was conducted by using heating oven, photo stability chamber and hot plate from Thermolab India.

\section{Chemicals and Reagents}

Pharmaceutical grade SAX was supplied by VerGo Pharma, Goa, India. While MET was supplied by Soham Healthcare Ltd India. Saxagliptin $\mathrm{HCl} 5 \mathrm{mg}$ and Metformin $\mathrm{HCl} 1000 \mathrm{mg}$ combination tablets were used for method verification which were purchased from Indian local market. All solutions were prepared with milli-Q-water. Acetonitrile was HPLC grade, Merck. Orthophosphoricacid was AR grade, Merck. Hydrochloric acid and sodium hydroxide pellets were GR grade, Merck. Hydrogen peroxide solution (30\% $\mathrm{w} / \mathrm{v})$, SDFCL India.

\section{Preparation of Diluent: (2:20:78 water: acetonitrile: methanol \% v/v)}

Mixed $20 \mathrm{~mL}$ water, $200 \mathrm{~mL}$ of acetonitrile and $780 \mathrm{~mL}$ of methanol and sonicated.

\section{Preparation of Standard}

Saxagliptin Standard solution stock: Weighed and transferred Saxagliptin $\mathrm{HCl}$ equivalent to $50 \mathrm{mg}$ of saxagliptin into a $50 \mathrm{~mL}$ flask and made up to volume with Diluent.

Standard solution of saxagliptin and Metformin: $-10 \mathrm{~mL}$ of above standard stock transferred into a 100 $\mathrm{mL}$ volumetric flask in which added about $40 \mathrm{mg}$ of metformin and made up to volume with Water.

\section{Tablet test sample Preparation}

Weighed 10 tablets to a $500 \mathrm{ml}$ volumetric flask to that added $10 \mathrm{ml}$ of water vortex for $5 \mathrm{~min}$ to dissolve the coating of tablets, added $100 \mathrm{~mL}$ acetonitrile vortex for $5 \mathrm{~min}$ checked for proper dispersion of tablets further added $300 \mathrm{~mL}$ of methanol and sonicate it for $10 \mathrm{~min}$ with vigorous shaking. Allow to equilibrate at room temperature and diluted to volume $500 \mathrm{~mL}$ with methanol. Centrifuged at 5000 RPM for 5 mins. Supernatant solution used as sample for Saxagliptin assay analysis and for Metformin analysis $2.0 \mathrm{ml}$ of centrifuged sample was transferred to $100 \mathrm{~mL}$ flask and made up to mark with water.

\section{Validation of developed Method}

The validation of developed method was done as per ICH guidelines. ${ }^{19}$

\section{System Suitability Parameters}

According to $\mathrm{USP}^{20}$ system suitability is an important part of chromatographic method. It's useful to confirm the reproducibility of the developed method. The system suitability parameters like \% RSD of five replicates injections, Theoretical plates and tailing for peaks were recorded which were found to be acceptable. The results are shown in Table 1.

\section{Specificity}

To show the good separation of SAX and MET from their impurities an experiment was conducted. To make sure the efficient separation of degradant peaks of excipients at the retention time of SAX and MET degradation of excipients was carried out. Formulation and placebo samples were separately exposed to various stress conditions to bring degradation. The formulation was exposed to alkaline hydrolysis by refluxing sample solution in $0.1 \mathrm{~N}$ sodium hydroxide at room temperature for $1 \mathrm{hr}$. Similarly the acidic hydrolysis was conducted 
by refluxing sample solution in $5 \mathrm{~N}$ hydrochloric acid at $60^{\circ} \mathrm{C}$ for $24 \mathrm{hr}$. The hydrolysis with water conducted by refluxing sample solution at temperature of $60^{\circ} \mathrm{C}$ for $24 \mathrm{hr}$. Oxidation was conducted by exposing sample to $30 \%$ hydrogen peroxide solution at $60^{\circ} \mathrm{C}$ for $2 \mathrm{hr}$. For Photo stability study, formulation kept in Petri-plates and was exposed to sunlight and UV light for 7 days. Humidity stress was conducted separately by exposing Formulation to humidity at $25^{\circ} \mathrm{C}, 90 \% \mathrm{RH}$ for 7 days. Thermal stress was conducted by heating formulation at $105^{\circ} \mathrm{C}$ for $24 \mathrm{hr}$. Placebo samples were also prepared like a formulation and exposed to condition same as formulation. Forced degradation placebo and samples were all injected into the chromatographic condition as per test method to show the spectral peak purity of peaks. Table 2 shows forced degradation data for SAX and MET.

\section{Accuracy}

Accuracy of method was performed by recovery study. Sample solutions were prepared by solid spiking at about $50 \%, 100 \%$ and $200 \%$ of test concentration level into placebo and it was then injected into developed method. The \%RSD for the tablet analysis was not more than $2.0 \%$ which shows a good accuracy. Recovery results tabulated in Table 3.

\section{Precision}

\section{System precision}

System precision is the measure of how closeness of agreement between a series of measurement under the same analytical condition. Mixed standard solution prepared was injected for six times. The $\%$ relative standard deviations were found to be $0.1 \%$ and $0.1 \%$ for SAX and MET respectively.

\section{Method Precision}

Method precision study was performed on six sample preparation as per test method. The $\%$ Relative Standard Deviation (RSD) found for SAX and MET were not more than $2.0 \%$ signifying high level of precision. Results tabulated in Table 4.

\section{Stability of solution}

Standard solution and sample were prepared and injected into chromatographic condition at initial and after $24 \mathrm{hr}$ fresh standard and same sample were injected to check the stability. The $\%$ RSD for peak areas was determined and found to be less than $2.0 \%$ which shows that stability of the solution at bench top.

\section{Filter Compatibility}

Sample solutions were prepared in triplicate as per the methodology. Filtered the sample solution with $0.45 \mu \mathrm{m}$

\begin{tabular}{|l|c|c|c|}
\hline \multicolumn{4}{|c|}{ Table 1: System Suitability Parameters. } \\
\hline Parameter & Limit & SAX & MET \\
\hline \% RSD of area of six injections & $\leq 2.0$ & 0.2 & 0.4 \\
\hline \% RSD of retention time of six injections & $<2.0$ & 0.3 & 0.2 \\
\hline Theoretical plates number (N) & $>2000$ & 5246 & 6458 \\
\hline Tailing Factor & $\leq 2$ & 1.1 & 1.3 \\
\hline Resolution & $\leq 1.5$ & -- & 4.68 \\
\hline Capacity Factor & 1 to 10 & 2.4 & 4.7 \\
\hline Selectivity Factor & $>1$ & -- & 1.93 \\
\hline HETP & Value should be & 0.0477 & 0.0387 \\
\hline
\end{tabular}

Table 2: Forced Degradation Data for Saxagliptin phosphate (SAX) and Metformin
Hydrochloride (MET).
\begin{tabular}{|c|c|c|c|c|c|c|}
\multirow{2}{*}{ Sample } & \multicolumn{2}{|c|}{$\%$ Assay } & \% Degradation & & \multicolumn{2}{c|}{ Peak Purity } \\
\cline { 2 - 7 } & SAX & MET & SAX & MET & SAX & MET \\
\hline Control & 100.5 & 100.6 & - & - & 1.00 & 1.00 \\
\hline Acid & 97.9 & 99.8 & 2.1 & 0.2 & 1.00 & 1.00 \\
\hline Base & 89.7 & 97.7 & 10.3 & 2.3 & 1.00 & 1.00 \\
\hline Oxidative & 90.6 & 89.1 & 9.4 & 10.9 & 1.00 & 1.00 \\
\hline Thermal & 85.6 & 99.8 & 14.4 & 0.2 & 1.00 & 1.00 \\
\hline Photolytic & 94.5 & 97.5 & 5.5 & 2.5 & 1.00 & 1.00 \\
\hline
\end{tabular}


mdi PVDF syringe filter, $0.45 \mu$ mdi Nylon 66 syringe filter and analyzed by method and calculated results against the standard. The relative standard deviation was calculated for obtained results and it was found to be less than $2.0 \%$ which shows suitability of filter.

\section{Linearity and Range}

Linearity was conducted from $10 \%$ to $200 \%$ of standard concentration. The standard stock solution was diluted from $10 \%$ to $200 \%$ concentration and the final solution for linearity of SAX prepared was 10 to $100 \mu \mathrm{g} / \mathrm{ml}$. Final solution for linearity of MET prepared was 40 to $800 \mu \mathrm{g} / \mathrm{ml}$. Injected $10 \mu \mathrm{L}$ of each level solution in duplicate into chromatographic condition. Calibration curve was plotted by response peak area versus the drug concentration at each level. The observations are shown in Table 5.

\section{Limit of Quantitation (LOQ) and Limit of Detection (LOD)}

The LOQ and LOD were estimated based on the calibration curves data. The residual standard deviation and slope from calibration data and were used in calculating as below formulae.

$$
\begin{aligned}
& \text { LOD }=3.3 \times \sigma / S \\
& \text { LOQ }=10 \times \sigma / S
\end{aligned}
$$

Where, $\sigma=$ standard deviation

$\mathbf{S}=$ slope

The LOD for SAX and MET were observed to be 0.354 and $2.546 \mu \mathrm{g} / \mathrm{mL}$ respectively. The LOQ for SAX and MET were observed to be 1.125 and $7.243 \mu \mathrm{g} / \mathrm{ml}$.

\section{Robustness}

The robustness was conducted by making small

\begin{tabular}{|c|c|c|c|c|c|}
\hline Drug & $\begin{array}{c}\text { Label } \\
\text { Claim } \\
\text { (mg/tab) }\end{array}$ & $\begin{array}{c}\text { Concentration } \\
\mu \mathrm{g} / \mathrm{mL}\end{array}$ & $\begin{array}{c}\text { Recovery } \\
\text { level } \\
\%\end{array}$ & $\begin{array}{c}\% \text { Recovery } \\
\text { Estimated } \\
\text { Mean (a) } \pm \text { SD (b) }\end{array}$ & $\%$ RSD (c) \\
\hline \multirow{3}{*}{ SAX } & \multirow{3}{*}{5} & 50 & 50 & $99.2 \pm 0.3456$ & 0.32 \\
\hline & & 100 & 100 & $99.6 \pm 0.5466$ & 0.78 \\
\hline & & 200 & 200 & $99.5 \pm 0.6485$ & 0.61 \\
\hline \multirow{3}{*}{ MET } & \multirow{3}{*}{1000} & 200 & 50 & $99.6 \pm 0.3564$ & 0.32 \\
\hline & & 400 & 100 & $100.2 \pm 0.2456$ & 0.18 \\
\hline & & 800 & 200 & $99.9 \pm 0.4561$ & 0.39 \\
\hline
\end{tabular}
deliberate changes in the developed method parameters

(a): Average of Three Determinations (b): Standard Deviation (c): Relative Standard Deviation

\begin{tabular}{|c|c|c|}
\hline Name & SAX & MET \\
\hline Range in $\mu \mathrm{g} / \mathrm{mL}$ & $10-200$ & $40-800$ \\
\hline Regression Equation & \multicolumn{2}{|c|}{$Y=A+B^{*} C$} \\
\hline Slope (B) & 13141.636 & 43772.483 \\
\hline Intercept (A) & 11225.237 & 226013.036 \\
\hline Correlation coefficient (r) & 0.9990 & 0.9993 \\
\hline
\end{tabular}

\begin{tabular}{|c|c|c|}
\hline \multicolumn{2}{|c|}{ Table 4: Results of Method precision. } \\
\hline Sample No. & \multicolumn{2}{|c|}{$\%$ Assay } \\
\hline & SAX & MET \\
\hline 1 & 99.2 & 99.5 \\
\hline 2 & 99.8 & 100.5 \\
\hline 3 & 100.2 & 99.7 \\
\hline 4 & 98.9 & 100.2 \\
\hline 5 & 99.5 & 99.3 \\
\hline 6 & 99.6 & 98.9 \\
\hline Mean \pm SD & $99.5 \pm 0.4546$ & $99.7 \pm 0.5879$ \\
\hline$\%$ RSD & 0.5 & 0.6 \\
\hline
\end{tabular}

C: Concentration in $\mu \mathrm{g} / \mathrm{ml}$ Y: Unit of Response Factor a: Standard Error

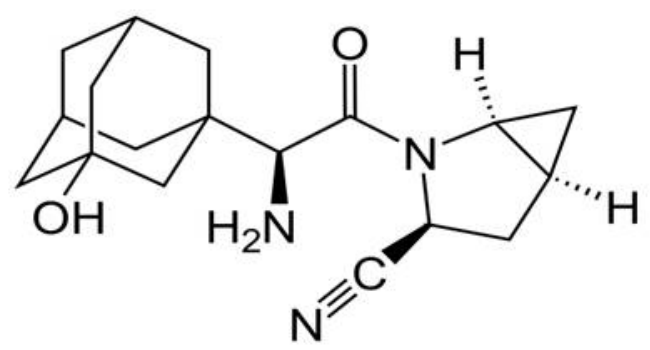

Figure 1a: Saxagliptin. 
like $\mathrm{pH} \pm 0.2$ units, mobile phase composition ratio \pm $5 \%$, column temperature \pm 5 units and flow $\pm 0.2 \mathrm{~mL} /$ min. There was no considerable change in percentage recoveries of drugs. The outcome of the robustness study shows that the method is robust as it is unaffected by small variations.

\section{RESULTS AND DISCUSSION}

An objective of this study was to develop an improved simple, selective, accurate, reproducible and sensitive stability indicating HPLC assay method for SAX and MET in bulk and pharmaceutical formulation. The reversed phase chromatography was selected for method development of SAX and MET. Ammonium dihydrogen phosphate salt selected for buffer preparation. Phenomenex Luna SCX column selected as stationary phase for retention of MET as MET do not retain in $\mathrm{C}_{18}$ column without using ion pair reagent in mobile phase. SCX column has modified stationary phase bonded with ion pair reagent which retains the analytes. Different buffer $\mathrm{pH}$, flow rate, column temperature and different composition of buffer: methanol and buffer: Acetonitrile with different ratios such as 55:45, 60:40, 70:30, 80:20 v/v were tried to separate SAX and MET the best retention and separation was got by using buffer $\mathrm{pH} 2.50$ : methanol $(70: 30, \mathrm{v} / \mathrm{v})$ with a flow rate of 1.8 $\mathrm{mL} / \mathrm{min}$ and column temperature $40^{\circ} \mathrm{C}$. Flow rate was kept $1.8 \mathrm{~mL} / \mathrm{min}$ so as to elute fast the analytes and reduce the run time of method. Column temperature kept at $40^{\circ} \mathrm{C}$ for better resolution, better peak shape of saxagliptin and metformin. Column temperature $25^{\circ} \mathrm{C}$ shows less resolution and late elution of peaks

\begin{tabular}{|c|c|c|c|c|}
\hline \multirow{2}{*}{$\begin{array}{c}\text { Parameters } \\
\text { Name }\end{array}$} & \multicolumn{2}{|c|}{ Proposed method } & \multicolumn{2}{|c|}{ Reported method ${ }^{27}$} \\
\hline & SAX & MET & SAX & MET \\
\hline Mean & 99.5 & 99.7 & 99.92 & 100.17 \\
\hline $\begin{array}{l}\text { Standard } \\
\text { deviation }\end{array}$ & 0.4546 & 0.5879 & 1.158 & 0.996 \\
\hline Variance & 0.2066 & 0.3456 & 1.341 & 0.992 \\
\hline $\mathbf{n}$ & 6 & 6 & 7 & 8 \\
\hline Student $t$ test & -0.8834 & 0.426 & & \\
\hline F value & 0.1541 & 0.3484 & & \\
\hline
\end{tabular}

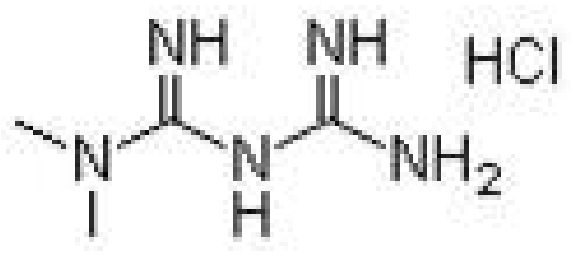

Figure 1b: Metformin $\mathrm{HCl}$. than $40^{\circ} \mathrm{C}$ column temperature. SAX elutes at about 6.2 min while MET elutes at about 10.3 min. Late elution kept so as to separate any degradation placebo peak or impurity peaks. Figure 2-3(a -k) shows typical of blank, placebo, standard and samples of SAX and MET. The retention times of SAX and MET were 6.3 and 10.4 min, respectively. Forced degradation studies were also studied in that acid stress, alkali stress, peroxide, heat, UV treatment given to SAX and MET. Chromatogram of base degradation of saxagliptin shown in Figure $3 \mathrm{j}$ and 3k. Peak purity of MET and SAX established in presence of all major degradation product in stressed samples. The calibration plot curve was linear over the range 10 to $200 \mu \mathrm{g} / \mathrm{ml}$ and 40 to $800 \mu \mathrm{g} / \mathrm{ml}$ for the detection of SAX and MET respectively. The correlation coefficients ( $r$ ) found was not less than 0.99 which shows method is linear statistically. Calibration curve shown in Figure $3 \mathrm{~h}$ and Figure $3 \mathrm{i}$ for saxagliptin and metformin respectively. The recovery at three different level concentrations of SAX and MET was performed, the relative standard deviation values of were less than $2.0 \%$.

The results obtained after analysis of SAX and MET by the developed methods were statistically compared with results of the reported methods. ${ }^{27}$ Statistical comparison

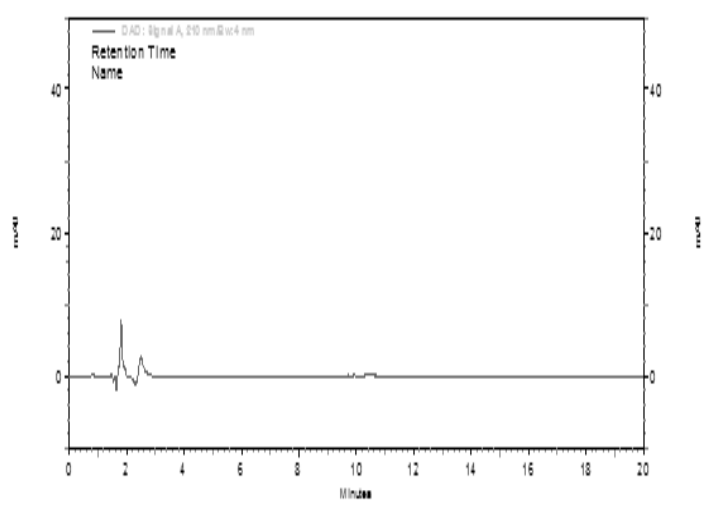

Figure 2: Chromatogram of Blank.

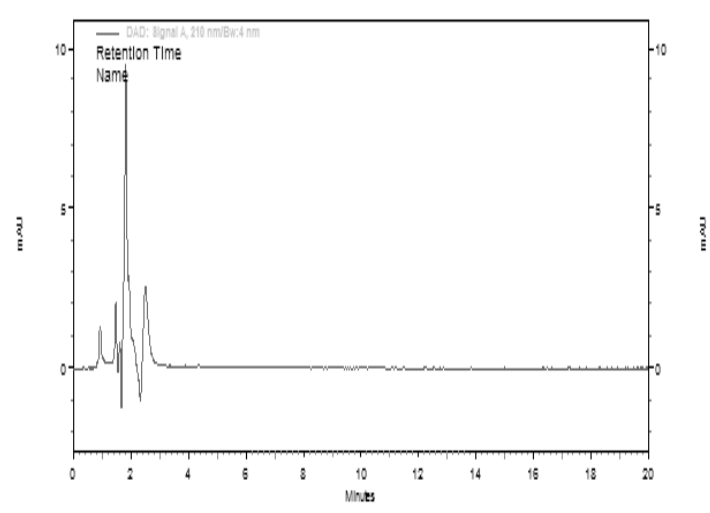

Figure 3a: Chromatogram of Placebo. 


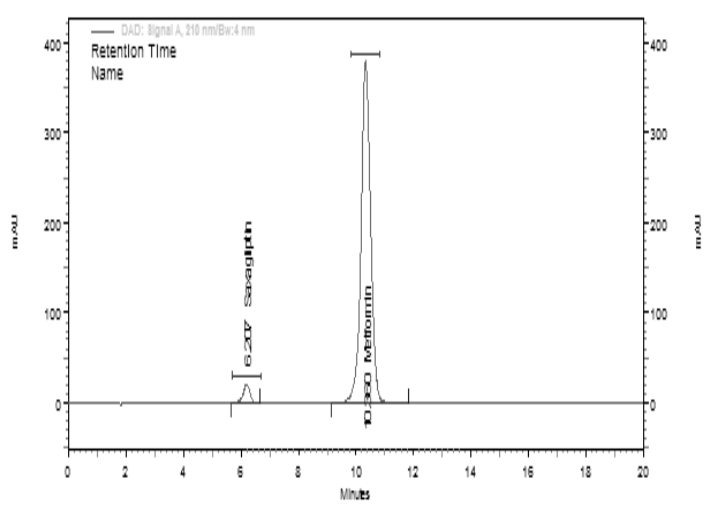

Figure 3b: Chromatogram of Standard solution Saxagliptin $(100 \mu \mathrm{g} / \mathrm{mL})$ and Metformin $(400 \mu \mathrm{g} / \mathrm{mL})$.

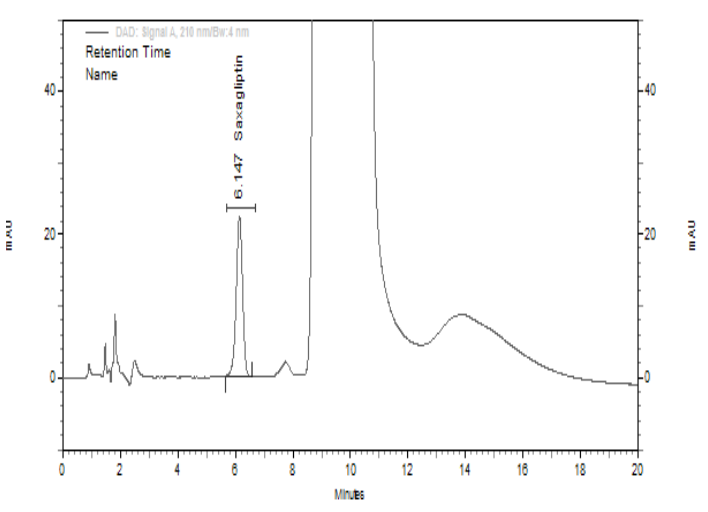

Figure 3c: Zoomed Chromatogram of Tablet Sample for Saxagliptin.

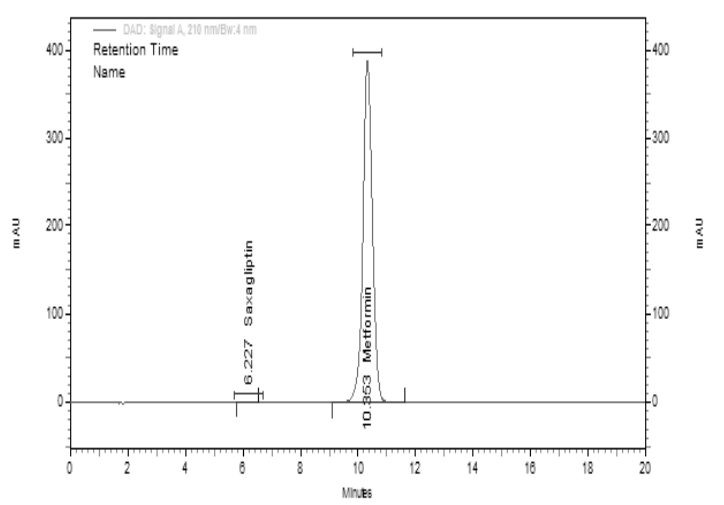

Figure 3d: Chromatogram of Tablet Sample for Metformin.

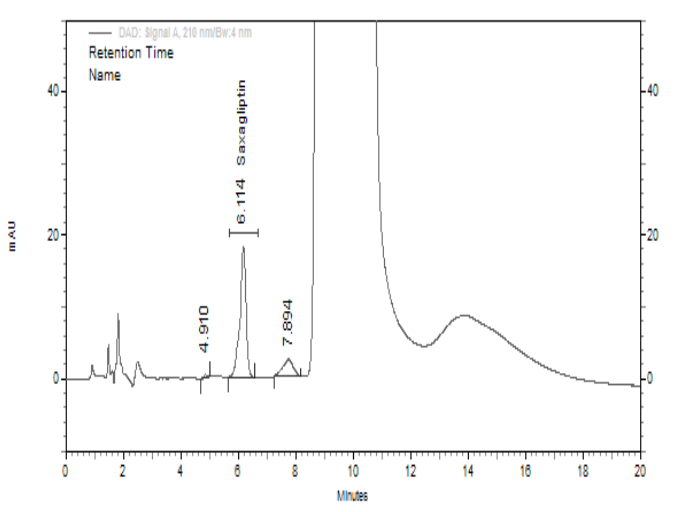

Figure 3e: Chromatogram of Base Degradation for Saxagliptin.

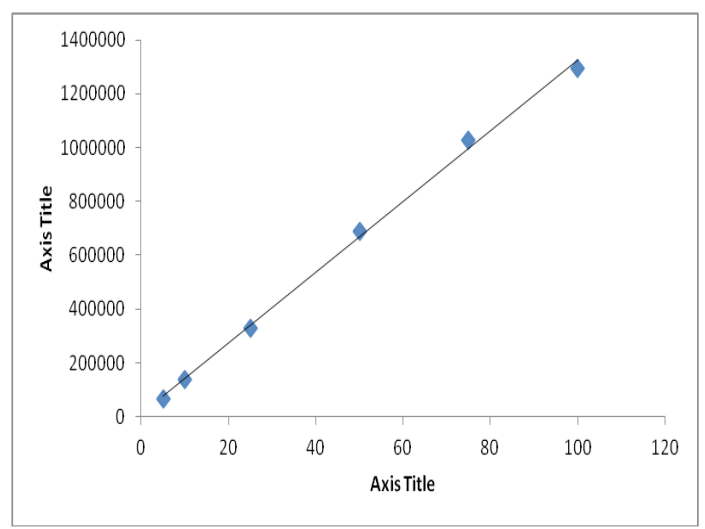

Figure 3h: Calibration curve for Saxagliptin Phosphate.

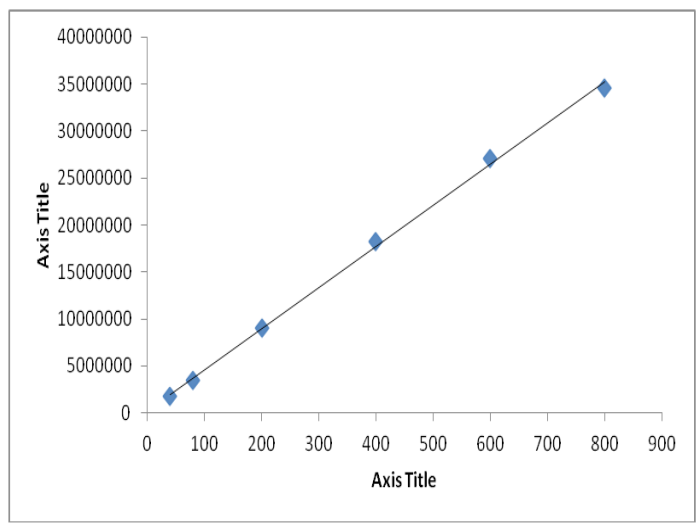

Figure 3i: Calibration curve for Metformin $\mathrm{HCl}$.

\begin{tabular}{|c|c|c|c|c|}
\hline \multicolumn{2}{|c|}{ Table 7: Comparison of parameter of developed method with reported method. } \\
\hline \multirow{2}{*}{ Parameter } & \multicolumn{2}{|c|}{ Developed Method } & \multicolumn{2}{c|}{ Reported method $^{27}$} \\
\cline { 2 - 5 } & SAX & MET & SAX & MET \\
\hline \multirow{2}{*}{ Range } & $10-200 \mu \mathrm{g} / \mathrm{mL}$ & $40-800 \mu \mathrm{g} / \mathrm{mL}$ & $1.5-25 \mu \mathrm{g} / \mathrm{mL}$ & $25-1000 \mu \mathrm{g} / \mathrm{mL}$ \\
\hline LOD & 0.354 & 2.546 & 0.478 & 8.178 \\
\hline LOQ & 1.125 & 7.243 & 1.447 & 24.782 \\
\hline
\end{tabular}




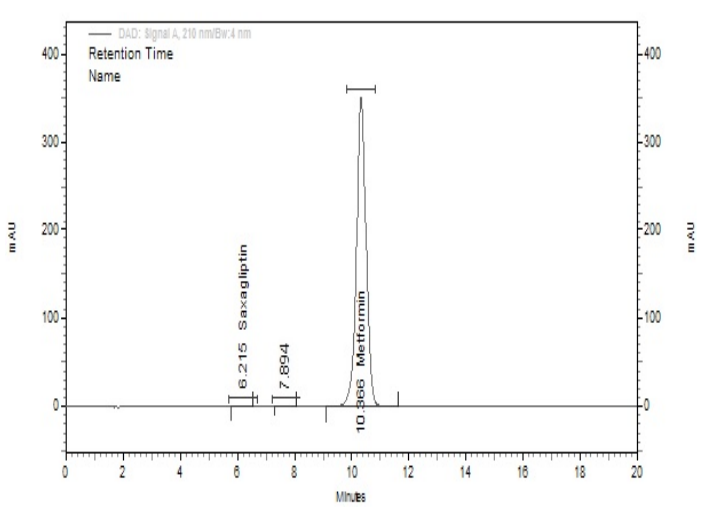

Figure 3j: Chromatogram of Base Degradation for Metformin.

shown in Table 6 . The calculated $\mathrm{t}$ and $\mathrm{F}$ values show that there is no considerable variation between the two methods with respect to accuracy and precision. The LOD and LOQ values in proposed method for both the drugs are less than that of reported method which indicates method is more sensitive than reported method. Proposed method shows good Linearity than that of reported method. Comparison shown in Table 7.

\section{CONCLUSION}

Developed Stability indicating HPLC method is selective, accurate, precise, sensitive, robust and selective and can be used for the simultaneous determination of SAX and MIT in pure form and pharmaceutical tablets formulations. Selective and increased detector detection shows method is more superior. A good recovery of method showed that there is no interference of excipients used in the formulations at analyte. The outcome of the validation study showed that the developed reverse phase HPLC method for SAX and MET can be used for routine analysis in QC departments for the simultaneous determination of the tablets containing SAX and MET.

\section{ACKNOWLEDGEMENT}

The authors are thankful to the Principal, Bharati Vidyapeeth College of Pharmacy, Kolhapur, for providing necessary facilities for research.

\section{CONFLICT OF INTEREST}

The authors declare no conflict of interest.

\section{ABBREVIATIONS}

SAX: Saxaglitin $\mathrm{HCl}$; MET: Metformin $\mathrm{HCl}$; ACN: Acetonitrile.

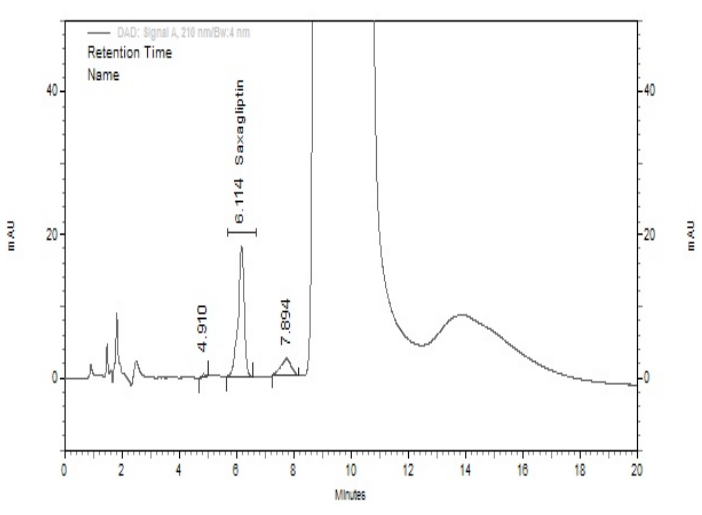

Figure 3k: Chromatogram of Base Degradation for Saxagliptin.

\section{REFERENCES}

1. Augeri DJ, Robl JA, Betebenner DA, Magnin DR, Khanna A, Robertson JG, et al. Discovery and preclinical profile of saxagliptin (BMS-477118): A highly potent, long-acting, orally active dipeptidyl peptidase IV inhibitor for the treatment of type 2 diabetes. J Med Chem. 2005;48(15):5025-37.

2. Campbell DB, Lavielle R, Nathan C. The mode of action and clinical pharmacology of gliclazide: A review. Diab Res Clin Prac. 1991;14(Suppl 2):S21-36.

3. Nyola N, Jeyabalan GS. Development and validation of uv-vis specctroscopy method for simultaneous estimation of saxagliptin hydrochloride and metformin hydrochloride in active pharmaceutical ingrident. J Pharm Educ Res. 2012;3:1-6.

4. Caglar S. A Validated High Performance Liquid Chromatography Method for the Determination of Saxagliptin and Metformin in Bulk, a Stability Indicating Study. J Anal Bioanal Tech. 2014;S6:1-5.

5. Cumar RP, Vasudevan M, Deecaraman. A Validated RP - HPLC Method for Simultaneous Estimation of Metformin and Saxagliptin in tablets. Rasāyan J Chem. 2012;5:137-41.

6. Patil PP, Kalkotwar RS, Patil VV, Jadhav VB, Patil NP. A new RP -HPLC method for determination of metformin $\mathrm{HCl}$ and saxagliptin in tablet dosage form. Inter J Pharm and Bio Sci. 2012;2(4):161-7.

7. Nglazi NN, Jeyabalan GS. Simultaneous estimation of saxagliptin hydrochloride and metformin hydrochloride in active pharmaceutical ingrident by RP-HPLC. AJPRHC. 2012;4(3):70-7.

8. Onal A. Spectrophotometric and HPLC determinations of anti-diabetic drugs, rosiglitazone maleate and metformin hydrochloride, in pure form and in pharmaceutical preparations. Euro J Med Chem. 2009;44(12):4998-5.

9. Florentin T, Monica A. Specificity of an Analytical HPLC Assay Method of Metformin Hydrochloride. Revue Roumaine De Chimie. 2007;52(6):603-9.

10. Madhukar A, Prince A, Vijay KR, Sanjeeva Y, Jagadeeshwar K, Raghupratap D. Simple And Sensitive Analytical Method Development And Validation of Metformin Hydrochloride By RP-HPLC. Int J Pharm Pharm Sci. 2011;3(3):11722.

11. Havele S, Dhaneshwar S. Development and Validation of A HPLC Method for the Determination of Metformin Hydrochloride, Gliclazide and Pioglitazone Hydrochloride in Multicomponent Formulation. Webmed Central Pharmaceutical Sciences. 2010;1(10):WMC001078.

12. Fatema K, Rahman MZ, Haque T, Abul KAM, Selim RM. Development and Validation of a Simple Method for Simultaneous Estimation of Metformin Hydrochloride and Gliclazide in Tablets by using Reversed Phase High Performance Liquid Chromatography. Dhaka Univ J Pharm Sci. 2010;9(2):839.

13. Klaczkow G, Anuszewska E. Determination of Impurities in Medical Products Containing Metformin Hydrochloride. Acta Poloniae Pharmaceutica: Drug Research. 2010;7(6):593-8. 
14. Georgița C, Sora I, Albu F, Monciu C. Comparison of A LC/MS Method With A LC/UV Method for the Determination of Metformin in Plasma Samples. Farmacia. 2010;58(2):158-9.

15. Bhamare PC, Bari SB, Natrajan S, Patil AA. Development and Validation of a precise single stability indicating HPLC method for determinations of Metformin hydrochloride and Fenofibrate, in Pure form and in Pharmaceutical tablets. Int J Pharm Tech Res. 2011;3(1):505-5.

16. Lakshmi KS, Rajesh T, Sharma S. Simultaneous Determination of Metformin and Pioglitazone by Reversed Phase HPLC in Pharmaceutical Dosage Forms. Inter J Pharm Pharm Sci. 2009;1(2):162-6.

17. Havaldar FH, Varial DL. Simultaneous Estimation of Metformin Hydrochloride, Rosiglitazone and Pioglitazone Hydrochloride in the Tablets Dosage Form. Inter J App Bio Pharm Tech. 2010;1(3):1000-5.

18. El-Bagary RI, Elkady EF, Fouad MA, El-Sherif ZA, Kadry AM, Ayoub BM Development and validation of a stability-indicating RP-LC method for the determination of Sitagliptin and Simvastatin in the presence of their degradation products in bulk drug mixture and combined pharmaceutical preparations. J Liq Chro Rel Tech. 2014;37:1895-108.

19. European Medicines Agency. International Conference on Harmonization $(\mathrm{ICH})$. Validation of Analytical procedures: Text and Methodology (Q2R1); Geneva: IFPMA. 2006;1-15.

20. United State pharmacopoeial convention, United State Pharmacopoeia, USP 34, NF29. 2011;1:248-50.

21. Ghazala K, Dinesh S, Agrawal YP, Neetu S, Avnish J, Gupta AK. Simultaneous Estimation of Metformin and Sitagliptin in Tablet Dosage Form. Asian J of Bio Pharm Res. 2011;2(1):353-8.

22. El-Bagary RI, Elkady EF, Ayoub BM. Spectroflourometric and Spectrophotometric Methods for the Determination of Sitagliptin in Binary Mixture with Metformin and Ternary Mixture with Metformin and Sitagliptin Alkaline Degradation Product. Int J Biomed Sci. 2011;7(1):62-7.
23. El-Bagary RI, Elkady EF, Ayoub BM. Liquid chromatographic determination of sitagliptin either alone or in ternary mixture with metformin and sitagliptin degradation product. Talanta. 2011;85(1):673-80.

24. Abdel-ghany MF, Abdel-aziz O, Ayad MF, Tadros MM. Stability-Indicating Liquid Chromatographic Method for Determination of Saxagliptin and Structure Elucidation of the Major Degradation Products Using LC - MS. J Chromatogr Sci. 2015;53:554-64.

25. Chhabda P, Balaji M, Srinivasarao V, Ramakrishna K, Apparao KMC Development and Validation of Simple Stability Indicating Rp-HPLC Method for Analysis of Saxagliptin and Its Forced Degradation Impurities in Bulk Drug and Pharmaceutical Dosage Form. Int J Res Dev Pharm Life Sci 2014; 3: 993-03.

26. Rao PS, Chandran DR, Murali K, Srinivasu S. Stability indicating Isocratic Reverse phase HPLC Method with PDA detector for the Estimation of Saxagliptin in bulk drugs and in its Formulation. Int J Pharma Sci 2013;3: 333-42.

27. Merey HA, Ramadan NK, Diab SS, Moustafa AA.Chromatographic methods for the simultaneous determination of binary mixture of Saxagliptin $\mathrm{HCl}$ and Metformin $\mathrm{HCl}$. Bulletin of Faculty of Pharmacy, Cairo University. 2017;55:311-7.

28. Blanco Jerez LM, Garcia Perez UM, Zambrano Robledo P. Carbon Paste Electrode Modified with BiVO4 to Sense Metformin. Int J Electrochem Sci. 2014;9:4643-52.

29. Gholiv MB, Mohammadi-Behzad L. Differential pulse voltammetric determination of metformin using copper-loaded activated charcoal modified electrode Anal Biochem. 2013, 438(1) 53-60

30. Abdallah NA, Ibrahim HF, Electrochemical determination of Saxagliptin hydrochloride with MWCNTs/CuO/4'aminobenzo-18-crown-6-ether composite modified carbon paste electrode Microchemical Journal 2019, 147, 487-96.

\section{PICTORIAL ABSTRACT}

DEVELOPMENT AND VALIDATION OF NOVEL STABILITY-INDICATING LC METHOD FOR THE DETERMINATION OF SAXAGLIPTIN AND METFORMIN

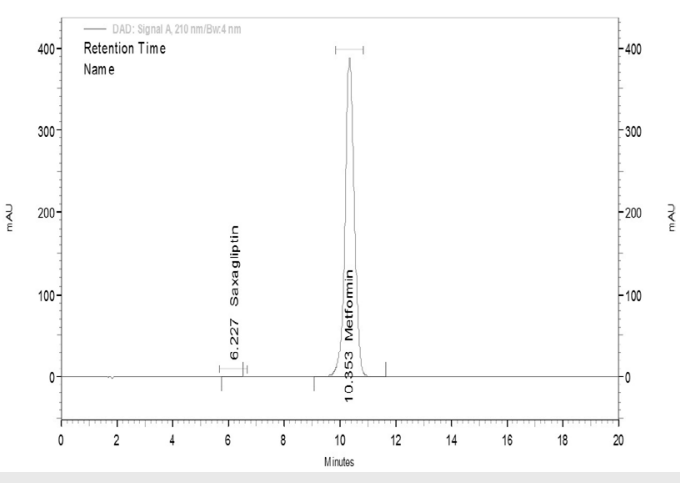

\section{SUMMARY}

A new reverse phase stability indicating HPLC method was developed and validated for quantification of Saxagliptin and Metformin from Tablets formulation. Method found specific, accurate precise for intended purpose.

Cite this article: Gurav SB, Bhatia NM. Development and Validation of Novel Stability-Indicating LC Method for the Determination of Saxagliptin and Metformin. Indian J of Pharmaceutical Education and Research. 2020;54(2s):s350-s357. 